Société d'histoire de la révolution de 1848 et des

révolutions du XIXe siècle

$24 \mid 2002$

Varia

\title{
Juan RIGOLI, Lire le délire. Aliénisme, rhétorique et littérature en France au XIXe siècle
}

Paris, Fayard, 2001, 649 p., 29,30€.

\section{Nicole Edelman}

\section{(2) OpenEdition}

Journals

Édition électronique

URL : http://journals.openedition.org/rh19/394

DOI : $10.4000 /$ rh19.394

ISSN : $1777-5329$

Éditeur

La Société de 1848

Édition imprimée

Date de publication : 1 juin 2002

Pagination : 200-203

ISSN : 1265-1354

Référence électronique

Nicole Edelman, « Juan RIGOLI, Lire le délire. Aliénisme, rhétorique et littérature en France au

XIXe siècle ", Revue d'histoire du XIXe siècle [En ligne], 24 | 2002, mis en ligne le 04 juin 2003, consulté

le 22 septembre 2020. URL : http://journals.openedition.org/rh19/394 ; DOI : https://doi.org/10.4000/ rh19.394

Ce document a été généré automatiquement le 22 septembre 2020.

Tous droits réservés 


\title{
Juan RIGOLI, Lire le délire. Aliénisme, rhétorique et littérature en France au XIXe siècle
}

Paris, Fayard, 2001, 649 p., 29,30€.

\author{
Nicole Edelman
}

Lire le délire. Aliénisme, rhétorique et littérature en France au XIX siècle est une œuvre-défi par l'ampleur de l'enquête qu'elle implique. Juan Rigoli, professeur de littérature française des XIX ${ }^{e}$ et XX $\mathrm{XX}^{\mathrm{e}}$ siècle à l'université de Fribourg (Suisse), interroge, en effet, de 1800 à 1860 , les textes d'auteurs dont l'ambition était "de lire le délire". Il s'agit d'une masse immense de documents, textes médicaux spécifiquement consacrés à la folie ou aux "passions", traités de séméiologie et de médecine légale, tableaux nosographiques mais aussi textes littéraires, essais de philosophie du langage, de grammaire, de poétique et de rhétorique, nouvelles, romans etc. Aussi Juan Rigoli restitue-t-il les doctrines des aliénistes du XIX siècle, du moins jusqu'en 1860, leur manière de penser et de comprendre la folie mais il fait aussi bien autre chose : il saisit "la manière dont la science psychiatrique a pris possession de son domaine, le style dans lequel elle a élaboré sa problématique et son discours. Il la montre à l'ouvrage dans la production de ses concepts. Mais il la montre aussi dans ses effets, c'est à dire la manière dont on l'a reçue" (Jean Starobinski, préface).

Aliénisme, rhétorique et littérature s'entrecroisent donc et une place particulière est donnée à l'analyse stylistique, d'autant que le premier rôle donné au délire oblige les aliénistes à une réflexion sur le langage et les écrits des aliénés que les médecins collectent à fin de citation. Juan Rigoli tend ainsi à montrer que la psychiatrie fonde sa pratique et construit son histoire sur et autour du langage. Les aliénistes entretiennent en effet un double rapport à la fois au langage et à l'écriture, puisqu'ils se représentent eux-mêmes en écrivains. Cependant si les contacts et les passages entre littérature et aliénisme sont nombreux, ils ne sont pas pour autant réciproques et "que le délire puisse se lire, c'est exactement ce qu'un Balzac, un Nodier ou un Nerval dénient". Le livre, issu d'une thèse de doctorat soutenue à l'université de Genève le 9 juillet 1999, est d'un foisonnement et d'une richesse extrêmes, multipliant les recoupements, les 
citations --très nombreuses et très longues-- et les références, développant des argumentations complexes et subtiles, mettant au jour les constructions, les tensions et les incertitudes conceptuelles dans le temps où elles se créent. Rendre compte de cet ouvrage est donc une gageure, aussi ne ferai-je qu'évoquer les grands axes de réflexion du livre qui s'organise autour de six séquences ou chapitres d'inégales longueurs. Le premier chapitre, "la folie à livre ouvert", rappelle le désir aliéniste (et plus largement médical) d'une "lecture de la pensée" qui s'appuierait sur un déchiffrement clinique de symptômes transformés en signes et sur une expertise légale de l'écrit. Rêve qui laisse supposer l'existence d'une grammaire et d'une rhétorique de la folie. Devant l'incertitude de l'identification de celle-ci et la nécessité de fonder la légitimité de leur savoir et de leur pratique, les aliénistes tentent alors de déployer, outre une symptomatologie de la folie, une stylistique de ses formes. C'est l'objet du deuxième chapitre, "Langage et symptomatologie". Juan Rigoli y développe l'étroite parenté entre médecine de l'esprit et rhétorique, l'aliénisme faisant de la parole un instrument thérapeutique, au sens où la parole dévoile les passions de l'âme, où elle est un moyen dont dispose la clinique aliéniste pour déceler l'aliénation. Le discours de la folie "tient lieu d'objet --le plus immédiat que les médecins puissent offrir-- pour l'observation des fous "tels qu'ils sont" et tels qu'ils parlent. La citation, autant que le portrait gravé qui illustre quelques-uns des grands traités, présentifie les aliénés et négocie la réception d'un discours qui entend montrer la folie, à défaut de pouvoir en énumérer les signes". Les aliénistes, en effet, se heurtent sans cesse à l'indicible de la folie.

Le troisième chapitre s'intitule "Les aliénés tels qu'ils sont". Mais justement qui sont ils ? Imprévisibles, changeants, divers, comment saisir les images qui les constituent ? Il s'agit de divulguer les représentations de la physionomie de l'aliéné. Voir. Observer. Visiter les asiles mais aussi lire les traités, car la lecture peut tenir lieu de visite et le discours médical reproduit et met en scène la parole de l'aliéné. Il "représente la folie", le foisonnement des portraits de fous, peints ou dessinés, en témoigne. Pourtant la complexité, les pièges d'une folie toujours en mouvement ne laissent qu'à l'aliéniste, et à lui seul, la capacité de lire le délire et de dire qui est fou et qui ne l'est pas. "Quel autre que le médecin ?" (chapitre 4). Puisqu'il est impossible d'énumérer les caractères de la folie, l'aliéniste demeure donc l'indispensable maître de ceux qui veulent lire le délire, il doit donc donner des leçons de lecture aux lecteurs de ses traités. Il demeure seul capable de vaincre cette "difficulté de saisir les formes variées et fugitives de la folie" (Esquirol). Pourtant, certains, nombreux, du juriste à l'observateur curieux, demandent à voir. En effet "quelle réalité peut avoir une folie dont l'évidence tient à l'excellence du regard qui la sonde ?" Aussi, "Les récits de folie" (chapitre 5), faits par les malades euxmêmes, ne pourraient-ils constituer infine un matériau pour fonder une connaissance de l'aliénation? Les aliénistes acceptent de travailler ces textes mais avec une extrême prudence et un très grand soin afin d'y retrouver par delà les "folies" de leur expression, la vérité de la folie.

Juan Rigoli examine longuement toutes ces formes d'écrits et les enjeux de leur interprétation, montrant comment peu à peu certains aliénistes en viennent eux mêmes à noter leurs propres pensées, leurs délires éventuels que certains provoquent par la prise, notamment, de haschisch. Jacques Moreau de Tours est ainsi la figure emblématique du médecin consommateur de cette "confiture verte" et de l'aliéniste rapportant ses auto-expérimentations, vivant de l'intérieur l'expérience de la folie. "Des aliénés peints par eux mêmes au portrait de l'aliéniste en "écrivain", la trajectoire qui se dessine est celle d'une connaissance doublée d'une conquête. Le champ du 
langage s'enrichit pour l'aliénisme d'une dimension nouvelle gagnée tout ensemble sur l'expression de la folie et sur l'institution littéraire : ce dont il s'est appliqué à faire un signe puis le relai d'une expérience, devient l'un des modes particuliers de l'exposition médicale, parallèlement, l'échange avec la littérature dont l'aliénisme tire en même temps ratification et prestige [...] devient l'instrument d'une annexion de la littérature par la médecine et d'une intégration de cette dernière dans l'espace culturel". Et dans cette avancée de l'aliénisme sur le terrain de la littérature, Juan Rigoli se demande dans un dernier chapitre, intitulé "Dissidences littéraires", quel parti l'institution littéraire a-t-elle pris ? Quel dialogue la littérature a-t-elle engagé avec cette médecine aliéniste ? En effet, dans le temps même --les années 1830-- où l'aliénisme reproduit le discours des aliénés, Balzac, Nodier, Gautier publient, comme en réplique, de nombreux textes qui se veulent très proches de la représentation de la folie que véhicule la nouvelle pathologie aliéniste. Juan Rigoli analyse alors longuement deux de ces textes : La Fée aux Miettes de Nodier et Louis Lambert de Balzac. Puis il se demande comment lire Nerval compte-tenu de sa "folie" pour terminer par une mise en regard de Louis Lambert et d'Aurélia et le dévoilement de sensibles convergences entre les deux textes, malgré "des positions radicalement différentes dans l'implication subjective qu'elles supposent, l'une en se situant dans une controverse scientifique, l'autre en s'efforçant d'esquiver la sanction de la science".

Lire le délire. Aliénisme, rhétorique et littérature en France au XIXe siècle franchit ainsi les frontières habituelles des disciplines, celle de l'histoire de la médecine et celle de la critique littéraire et plus largement celles de l'histoire et de la littérature. De la médecine à la littérature, en un va et vient qui s'accentue au cours des pages, ce livre dégage "les articulations d'une lecture, et plus globalement d'un rapport au langage, dans lesquels l'aliénisme s'est lui-même tenu constamment au point de rencontre de la littérature et de la médecine". Ce dialogue étroit, dans un jeu de miroir subtil et trompeur, fut sans doute porté par l'interprétation de la folie qui postule une non organicité de l'aliénation pendant ces quelques décennies de la première moitié du XIX ${ }^{e}$ siècle, Philippe Pinel parlant de "lésions" de l'entendement et de la sensibilité qui permettent, puisqu'elles ne sont pas troubles organiques, de justifier une thérapeutique morale grâce à une relation possible avec l'aliéné. Juan Rigoli affirme que le tournant organiciste de l'interprétation de la folie des années 1850, s'il ne met pas fin à cet échange, en modifie le cadre et la portée et prend donc une importance culturelle jamais encore mise en lumière, la première moitié du XIX siècle demeurant un moment inaugural. "La fin du siècle verra se redéfinir, avec Freud, à la fois la clinique du langage et le rapport de celle ci à la littérature. Non sans une continuité, par delà ce qui s'est imposé comme un révolution ou un commencement absolu, avec le champ psychiatrique". Freud, ainsi, jouera avec le texte de Jensen, dans Le délire et les rêves dans la "Gradiva" de Jensen renouant avec ce que certains aliénistes avaient inauguré avant lui.

Enfin, si Juan Rigoli, en interrogeant la psychiatrie à partir de la littérature, en révèle sa dimension littéraire, il questionne aussi en retour la place de la littérature. "La lecture de la lecture médicale, conclue-t-il, en cherchant son chemin à travers les passages et les métissages qui unissent la littérature et la médecine, aura donc été inévitablement portée, dans son propre exercice, à déplacer l'horizon du fait littéraire". 